\title{
High-pressure Cold Isostatic Pressing of Ultra-fine Oxide Powders $\dagger$
}

\author{
Hidehiro Kamiya**, Chiaki Nakayama and \\ Genji Jimbo \\ Department of Chemical Engineering, Nagoya University*
}

\begin{abstract}
Fine $\mathrm{Al}_{2} \mathrm{O}_{3}, \mathrm{MgO}$ and $\mathrm{SiO}_{2}$ powders of various sizes were consolidated into a dense and uniform structure by high-pressure cold isostatic pressing. Although the average particle diameter was less than $21 \mathrm{~nm}, \mathrm{Al}_{2} \mathrm{O}_{3}, \mathrm{MgO}$ and $\mathrm{SiO}_{2}$ powder compacts were compressed to $60 \%$ of their theoretical density by cold isostatic pressing at $1 \mathrm{GPa}$, because the open and strong aggregate structure collapsed under the cold isostatic pressure. The pore size of these compacts decreased below the primary particle size. Especially, in the case of $\mathrm{MgO}$ powders, the maximum relative density increased to $80 \%$ and the ratio of pore size to primary particle size was less than $20 \%$. However, in the case of $\mathrm{Al}_{2} \mathrm{O}_{3}$ powders, whose size was more than 100 $\mathrm{nm}$, a slight increase in relative density and decrease in pore size in the compacts occurred with an increase in isostatic pressure up to $1 \mathrm{GPa}$. In the case of particles larger than $100 \mathrm{~nm}$ and high-hardness materials, high cold isostatic pressure was not effective in increasing the packing density.

The mean vertical force and compressive stress at the contact point between particles in compacts and the maximum tensile stress in a particle during isostatic pressing were estimated using Rumpf's and Hertz's equation. Because these stresses were smaller than the hardness and tensile strength of $\mathrm{Al}_{2} \mathrm{O}_{3}$ or $\mathrm{MgO}$ materials, no viscous deformation or fracture of particle took place during compacting. The relations between the ratio of mode pore diameter to particle diameter and the relative density of $\mathrm{Al}_{2} \mathrm{O}_{3}, \mathrm{MgO}$ and $\mathrm{SiO}_{2}$ compacts agreed with those of spherical and monosized particle beds. The main mechanism of densification of compacts during isostatic pressing was the collapse of aggregates and rearrangement of particles.
\end{abstract}

\section{Introduction}

To improve the sintering qualities of inorganic type powders used in ceramics etc., and to obtain ceramics with a fine structure at low sintering temperatures, the reduction of particle size of raw material powders, and the increase in the physical activities of noncrystal or of particles without complete cyrstalization are effective ${ }^{5)}$. However ultra-fine particles with a particle size of $0.1 \mu \mathrm{m}$ or less readily form a strong and coarse aggregate structure in general and compacting of a dense, uniform structure is difficult. Therefore refinement and high activation of particles does not necessarily lead to obtaining dense sintered compacts under low temperature conditions.

* Furo-Cho, Chikusa-ku, Nagoya, 464-01 Japan

** Now with Tokyo University of Agri. \& Tech., Koganei, Tokyo 184 Japan

$\dagger$ This report was originally printed in Kagaku Kougaku Ronbunshu, 19, 220 (1993) in Japanese, before being translated into English with the permission of the editorial committee of the Soc. Chemical Engineers, Japan.
It is believed that $\mathrm{pH}$ control in water and colloid scientific methods using surface active agents are effective in collapsing and dispersing the strong aggregate structure of ultra-fine particles ${ }^{7,13,15)}$. However with ultra-fine particles of less than $100 \mathrm{~nm}$, the dispersion of aggregates by these methods is extremely difficult and this has not been successful except for cases of particles with special surface conditions such as $\mathrm{SiO}_{2}$ fine particles, formed from metallic alkoxide ${ }^{6)}$. Another effective method to collapse aggregate structures of ultra-fine particles is by compacting using ultra high pressure. Gleiter et $\mathrm{al}^{4,8)}$ compacted a gaseous phase ultra-fine particle to several $\mathrm{nm}$ particle diameter formed under a very high vacuum of $10^{-6}$ torr by applying a maximum of $5 \mathrm{GPa}$ uniaxial pressure, and succeeded in producing a dense bulk body (nanocrystalline) with a crystal particle size of several $\mathrm{nm}$ without sintering. However this method used by Gleiter et al requires a large scale apparatus 
involving high costs and since it is by uniaxial compacting, a uniform structure cannot be obtained. Therefore, as reported previously ${ }^{6}$, the authors produced a granulated powder resembling a closely packed structure by the spray drying method from spherical mono-dispersed silica fine particles of not more than $0.1 \mu \mathrm{m}$, formed from metallic alkoxides by isostatic pressing at $1 \mathrm{GPa}$, and obtained a Green body with a maximum relative density of $78 \%$.

Furthermore, the authors heat treated mullite precursor ultra-fine particles of not more than $10 \mathrm{~nm}$, synthesized from metallic alkoxide at not more than $1000^{\circ} \mathrm{C}$ by which the amorphous phase remains and the particle size hardly increases, then conducted isostatic pressing at $1 \mathrm{GPa}^{5}$. As a result, a Green body with a relative density of $60-70 \%$ was obtained, and at a sintering temperature less than the liquid phase formation temperature of $1,500^{\circ} \mathrm{C}$ which is lower by $200^{\circ} \mathrm{C}$ than normal, the density was increased to $98 \%$ and above to obtain a mullite sintered compact with an average crystal particle size of not more than $100 \mathrm{~nm}$. High activity ultra-fine particles were prepared and using a method to collapse the aggregate structure by a high pressure of $1 \mathrm{GPa}$, a ceramic (nano structure sintered compact) having an ultra-fine structure, sintered and densified at a relatively low temperature was produced. However the ultra-fine particles synthesized from metallic alkoxide possessed better dispersion qualities in water compared with particles produced by other methods and even though made of ultra-fine particles, they aggregate very much. In this report, to study whether the aggregate structure of ultra-fine particles made by other methods or from other materials would collapse by isostatic pressing and whether improvement of densification or sintering qualities of compacts could be obtained, ultra-fine particles of oxides with various diameters, made by various methods and from raw materials other than metallic alkoxides were used. Then the particle size and particle material which affect the densification process of compacts following an increase in isostatic pressure were studied and a quantitative study of the densified structure was attempted.

\section{Experiments}

Three kinds of oxide type fine particles, $\mathrm{Al}_{2} \mathrm{O}_{3}$, $\mathrm{MgO}$, and $\mathrm{SIO}_{3}$ were used. Their specific surface area $\left(S_{W}\right)$, density $\left(\varrho_{T}\right)$, specific surface area converted diameter $\left(d_{B}\right)$ calculated using Eq. (1) and crystal structure are summarized in Table 1.

$d_{B}=6000 /\left(S_{W} \varrho_{\tau}\right)$

The specific surface area was measured by the BET method by nitrogen adsorption while the crystal structure was measured by an $\mathrm{X}$ ray analysis method (XRD method). $\mathrm{Al}_{2} \mathrm{O}_{3}$ (I) is $\alpha-\mathrm{Al}_{2} \mathrm{O}_{3}$ (Made by Showa Denko, AL160SG) made by de-alkalizing the powder obtained by the Bayer method, while $\mathrm{Al}_{2} \mathrm{O}_{3}$ (II) to (IV) are high purity $\mathrm{Al}_{2} \mathrm{O}_{3}$ (Made by Daimei Chemical, TM-D, TM-100, and TM-300) obtained by thermal decomposition of $\mathrm{NH}_{4} \mathrm{AlCO}_{3}(\mathrm{OH})_{2}$. I and II whose specific surface area equivalent particle diameters $\left(d_{B}\right)$ are not less than $100 \mathrm{~nm}$, are $\gamma-\mathrm{Al}_{2} \mathrm{O}_{3}$ (trigonal system) while III and IV of 12.2 , and $5.6 \mathrm{~nm}$ are $\gamma-\mathrm{Al}_{2} \mathrm{O}_{3}$ (cubic system). It has been confirmed that $\gamma-\mathrm{Al}_{2} \mathrm{O}_{3}$ is rearranged by differential thermal analysis to $\alpha-\mathrm{Al}_{2} \mathrm{O}_{3}$ at a temperature of around $1150^{\circ} \mathrm{C}$. $\mathrm{Ob}$ -

Table 1 Powder properties of raw materials.

(A) $\mathrm{Al}_{2} \mathrm{O}_{3}$

\begin{tabular}{cccccc} 
Sample No. & $\mathrm{S}_{\mathrm{W}}\left[\mathrm{m}^{2} / \mathrm{g}\right]$ & $\varrho_{T}\left[\mathrm{~g} / \mathrm{cm}^{3}\right]$ & $d_{B}[\mathrm{~nm}]$ & purity [\%] & phase \\
\hline II & 5.6 & 3.98 & 269 & 99.4 & Trigonal $\left(\alpha-\mathrm{Al}_{2} \mathrm{O}_{3}\right)$ \\
II & 14.0 & 3.98 & 108 & 99.99 & Trigonal $\left(\alpha-\mathrm{Al}_{2} \mathrm{O}_{3}\right)$ \\
III & 134 & 3.67 & 12.2 & 99.99 & Cubic $\left(\gamma-\mathrm{Al}_{2} O_{3}\right)$ \\
IV & 290 & 3.67 & 5.6 & 99.99 & Cubic $\left(\gamma-\mathrm{Al}_{2} \mathrm{O}_{3}\right)$
\end{tabular}

(B) $\mathrm{MgO}$

\begin{tabular}{cccccc} 
Sample No. & $\mathrm{S}_{\mathrm{W}}\left[\mathrm{m}^{2} / \mathrm{g}\right]$ & $\varrho_{T}\left[\mathrm{~g} / \mathrm{cm}^{3}\right]$ & $d_{B}[\mathrm{~nm}]$ & purity [\%] & phase \\
\hline I & 8.4 & 3.58 & 199 & 99.9 & Cubic \\
II & 18.0 & 3.58 & 94 & 99.9 & Cubic \\
III & 37.0 & 3.58 & 45 & 99.9 & Cubic \\
IV & 168 & 3.58 & 10 & 99.9 & Cubic
\end{tabular}

\begin{tabular}{cccccc} 
(C) $\mathrm{SiO}_{2}$ & & & & \\
Sample No. & $\mathrm{S}_{\mathrm{W}}\left[\mathrm{m}^{2} / \mathrm{g}\right]$ & $e_{T}\left[\mathrm{~g} / \mathrm{cm}^{3}\right]$ & $d_{B}[\mathrm{~nm}]$ & purity [\%] & phase \\
\hline I & 128 & 3.20 & 21 & 99.9 & amorphous \\
II & 284 & 3.20 & 9.6 & 99.9 & amorphous
\end{tabular}


servation by an electron microscope shows that all the particles are aggregated but the primary particle sizes are relatively uniform.

$\mathrm{MgO}$ were all particles obtained by vapor oxidation of magnesium (Made by Ube Kosan, 2000A, 1000A, $500 \mathrm{~A}$, and $100 \mathrm{~A}$ ) with particle size controlled by the reaction conditions ${ }^{10)}$. Observations by an electron microscope confirmed that $\mathrm{MgO}$ (I) consisted of a mixture of particles of around $0.1-0.5 \mu \mathrm{m}$ formed into a cubic shape and fine particles of several $10 \mathrm{~nm}$. Even with $\mathrm{MgO}$ (II) and (III), the particle diameters are smaller than those of $\mathrm{MgO}$ (I) but cubic shape particles were observed ${ }^{10)}$. MgO (IV) did not contain cubic particles and consisted only of fine particles and a relatively uniform particle size distribution was observed. The particle size distribution is fairly widespread compared with $\mathrm{Al}_{2} \mathrm{O}_{3}$ but the specific surface area converted diameter $\left(d_{B}\right)$ was taken as representative of the particle diameter.

$\mathrm{SiO}_{2}$ was made by hydrolysis in oxyhydrogen flame of a volatile silane compound (Made by Nippon Aerosil, AEROSIL-130, 380). The specific surface area equivalent particle sizes were $21,9.6 \mathrm{~nm}$ and the fine particles were amorphous. Seen by an electron microscope, they were similar to $\mathrm{Al}_{2} \mathrm{O}_{3}$ (III), (IV) and $\mathrm{MgO}$ (IV) in that they were ultra-fine particles with a relatively uniform particle size.

The raw material powders were put in a metal mold of $20 \mathrm{~nm}$ and preparatory uniaxial compacting was performed for 3 minutes at $6.2 \mathrm{MPa}$. Then under conditions ranging from 0.05 to $1 \mathrm{GPa}$, isostatic compacting was conducted for 3 minutes. The powder density and pore size distribution of the compacts were evaluated by the mercury press method.

\section{Results}

\subsection{Changes in compact density by isotropic high pressure compacting}

Figs. 1(a) and (b) show the relation between the isostatic compacting pressure and the relative density after compacting $\left(\varrho_{G} / \varrho_{T}\right)$. Out of the four types of $\mathrm{Al}_{2} \mathrm{O}_{3}$ particles, $\mathrm{Al}_{2} \mathrm{O}_{3}$ (I) and (II) whose particle diameters were not less than $100 \mathrm{~nm}$ reached a relative density of $46.7 \%$ in the uniaxial compacting stage $\left(p_{C}=0 \mathrm{GPa}\right)$. However the increase in density accompanying an increase in pressure was slight and even when a pressure up to $1 \mathrm{GPa}$ was applied, a density increase of only around $10 \%$ compared with the case of metal mold forming was observed. On the other hand, with $\gamma-\mathrm{Al}_{2} \mathrm{O}_{3}$ III and IV with a particle size of 12.2 and $5.6 \mathrm{~nm}$, the relative density at

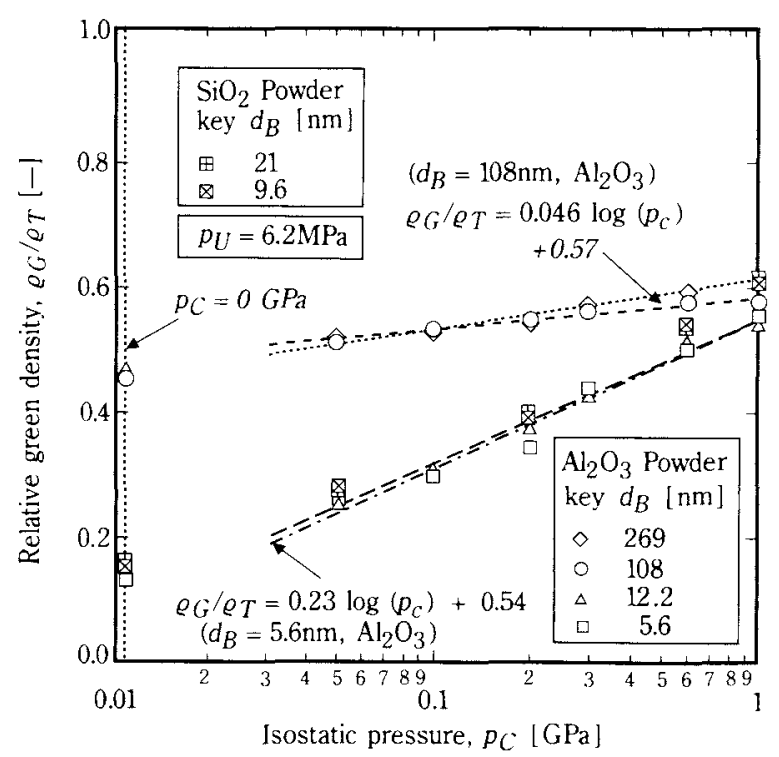

(a) $\mathrm{Al}_{2} \mathrm{O}_{3}$ and $\mathrm{SiO}_{2}$ powders

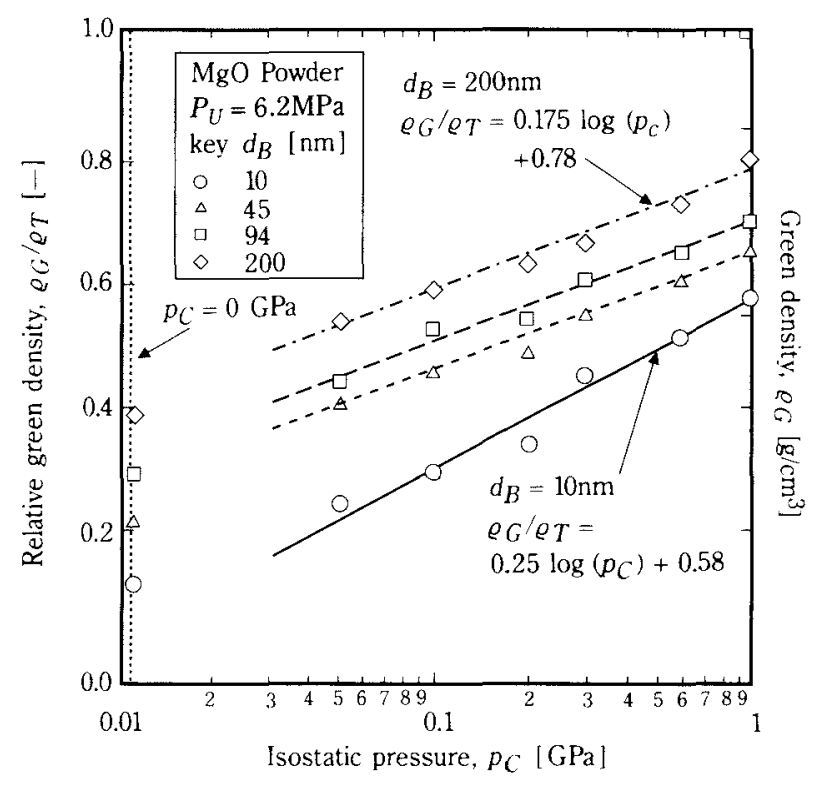

(b) $\mathrm{MgO}$ powder

Fig. 1 Change in the relative density of compacts with cold isostatic pressure. Uni-axial pre-pressing pressure $\left(p_{U}\right)$ was $6.2 \mathrm{MPa}$.

$60 \%$ was reached, roughly comparable to that of (I) and (II). With any of the powders, the relation between the relative density $\left(\varrho_{G} / \varrho_{T}\right)$ and the compacting pressure was linear on a semi-logarithmic graph like the following equation using constants $a$ and $b$.

$\varrho_{G} / \varrho_{T}=a \log \left(p_{C}\right)+b$ 
The slope with (I) and (II) was about 0.05 but with (III) and (IV), it was about 0.25 or fivefold more. In the Figure, the results on $\mathrm{SiO}_{2}$ of particle diameters $21,9.6 \mathrm{~nm}$ are also shown and they roughly coincide with the results of $\mathrm{Al}_{2} \mathrm{O}_{3}$ (III) and (IV).

In the case of $\mathrm{Al}_{2} \mathrm{O}_{3}$ (I) and (II) for which the particle size was not less than $100 \mathrm{~nm}$, the application of pressure was not very effective in increasing the density of compacts. Even with $\mathrm{SiC}$ and the like which are non-oxide particles, results with which isostatic pressures up to $900 \mathrm{MPa}$ were applied have been reported ${ }^{1,2)}$, but since the particle size was around $100 \mathrm{~nm}$ and above, a notable density increase following the application of pressure was not observed. However with fine particles of $2,30 \mathrm{~nm}$ and less, the application of isostatic pressure was extremely effective in increasing the compact density, not only for $\mathrm{Al}_{2} \mathrm{O}_{3}$ but for $\mathrm{SiO}_{2}$ and for those shown in Fig. 1(b) such as $\mathrm{MgO}$. Even with a pressure of $1 \mathrm{GPa}$, the density increase limit was not reached and with a pressure increase above $1 \mathrm{GPa}$, further densification can be expected.

Also with $\mathrm{MgO}$, the slope was the steepest in the relation between the relative density of the smallest particle size MgO (IV) and pressure (Fig. 1(b)). Also, it roughly coincides with the relation between compact pressures of $\mathrm{Al}_{2} \mathrm{O}_{3}$ (III), (IV), $\mathrm{SiO}_{2}$ and their relative density, while for particle sizes of not more than $21 \mathrm{~nm}$, the effect of material was hardly observed in the relation between the compact pressure and the relative density $\left(\varrho_{G} / \varrho_{T}\right)$. On the other hand, when the particle size was $45 \mathrm{~nm}$ (III), although not as conspicuous as with $\mathrm{Al}_{2} \mathrm{O}_{3}$, the slope compared with that of (IV) became somewhat flatter. With $\mathrm{MgO}$ (I) and (II) with an even larger particle size, the slope hardly changed. As the particle size became larger, the relative density following uniaxial compacting became higher and the slope did not become flat as much as that for $\mathrm{Al}_{2} \mathrm{O}_{3}$ and therefore, under a pressure condition of $1 \mathrm{GPa}$, the maximum relative density of $\mathrm{MgO}$ (I) reached $80 \%$. In the case of $\mathrm{MgO}$, even with a particle size of $100 \mathrm{~nm}$ and above, the slope in the relation between the relative density and pressure, as with $\mathrm{Al}_{2} \mathrm{O}_{3}$, was of a mechanism where as it did not become flatter compared with that of ultra fine particles with particle size of $21 \mathrm{~nm}$ and less, and the following 2 points are conceivable for this mechanism. The first is that for $\mathrm{MgO}$ (I) to (III), the particle size distribution is widespread and therefore the mechanism where small particles intrude into the space of large particles effectively functions even in high pressure stages. Secondly, the hardness of $\mathrm{MgO}$ is lower compared with that of $\mathrm{Al}_{2} \mathrm{O}_{3}$ and $\mathrm{MgO}$ is more liable to plastic deformation whereby deformation develops at the particle contact points under high pressure conditions. When the densification mechanisms of compacts in the pressurizing process change following a rearrangement of particles to the second mechanism which is a deformation of particles, a change is seen in the slope of Equation (2) and it was reported that it could not be approximated by one straight line ${ }^{11}$. However within the stress scope of the present study, no change was observed in the slope even under high pressure conditions near 1 $\mathrm{GPa}$ and both slopes of $\mathrm{MgO}$ and $\mathrm{Al}_{2} \mathrm{O}_{3}$ were approximated by a single straight line. Consequently, in the densification mechanism, the rearrangement of primary particles is dominant within the stress scope of the present study and it can be presumed that densification by plastic deformation of particle contact points is not dominant. The particle distribution of $\mathrm{MgO}$ (I) - (III) compared with that of $\mathrm{Al}_{2} \mathrm{O}_{3}$ (I), (II) is more widespread and it is believed that because the mechanism of small particles intruding into the space of large particles functions effectively, the relative density increases. To observe these mechanisms, attention was focused on the pore size distribution to study the changes in the compact structure during isostatic pressure application.

\subsection{Changes in pore size distribution in com- pacts during pressure application}

Figs. 2(a) and (b) show changes of pore size distribution accompanying the increase in isostatic compacting pressure of $\mathrm{Al}_{2} \mathrm{O}_{3}$ (II) and (III). During the metal mold forming stage, $\left(p_{C}=0 P G a\right)$, pores larger than the primary particle size $\left(d_{B}=108 \mathrm{~nm}\right)$ were present in $\mathrm{Al}_{2} \mathrm{O}_{3}$ (II) but by applying a low isostatic compacting pressure of only $0.05 \mathrm{GPa}$, pores larger than the primary particle size became hardly observable (Fig. 2(a)). Even by increasing the compacting pressure, not only the pore volume but the pore diameters were not appreciably reduced. With powders having a particle size of $100 \mathrm{~nm}$ or larger, almost all aggregate structures collapse under a relatively low pressure and a dense compact structure is acquired. Since a dense primary particle arranged structure already exists in the low pressure stage, rearrangement of particles is minimal even with an increase in pressure. It is thought that the near completion of particle rearrangement in the low pressure stage which is the densification mechanism of compacts, is the reason for the flat slope angle of $\mathrm{Al}_{2} \mathrm{O}_{3}$ (I) and (II) in Fig. 1(a).

On the other hand, with $\mathrm{Al}_{2} \mathrm{O}_{3}$ (III) having ultra- 


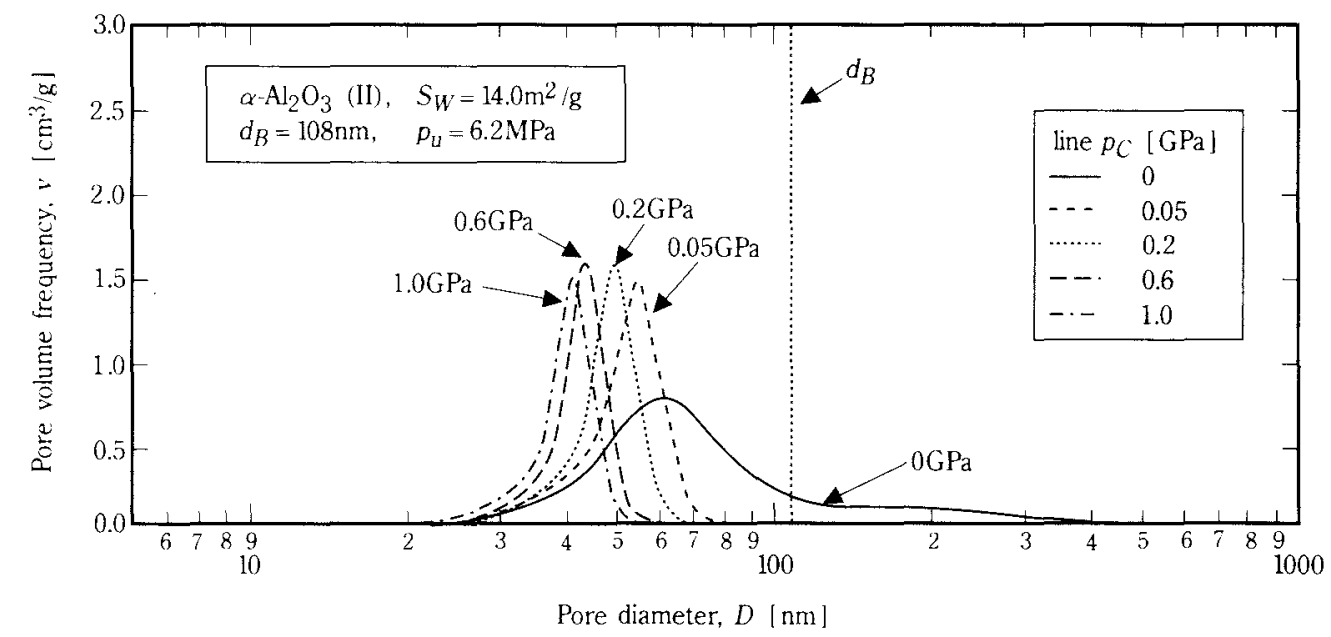

(a) $d_{B}=108 \mathrm{~nm}, S_{\mathbf{w}}=14 \mathrm{~m}^{2} / \mathrm{g}$

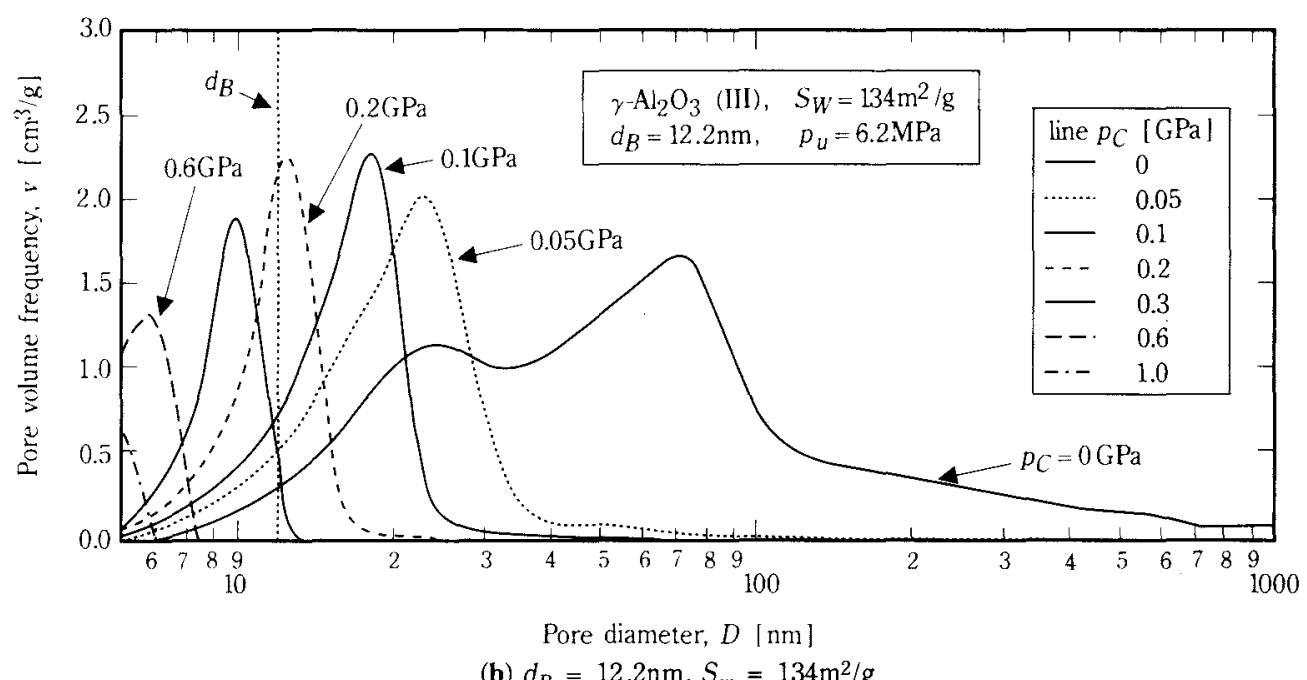

Fig. 2 Pore size distribution in compacts of $\mathrm{Al}_{2} \mathrm{O}_{3}$ powders measured by mercury porosimetry

fine particles with primary particle size of $12.2 \mathrm{~nm}$, pores with sizes 10 times larger than the primary particle size exist in the low pressure stage, indicating that aggregate structures have not collapsed (Fig. 2(b)). However with an increase in pressure, the pore diameters decrease and at $0.3 \mathrm{GPa}$, the pore diameters become about the same as the primary particle diameters. Then under high pressure conditions of $0.6 \mathrm{GPa}$ and above, the pore diameters become smaller than the primary particle diameters. Aggregate structures of ultra-fine particles of around $20 \mathrm{~nm}$ and smaller do not collapse under low pressures but with an increase in pressure, they collapse and become deformed. At $1 \mathrm{GPa}$, the mode pore size is smaller than $6 \mathrm{~nm}$ which is the measurement limit set for the mercury pressure fitting method adopted in this report, and reaches a size $60 \%$ or less of the primary particle diameter $\left(d_{B}\right)$ which does not differ much from the ratio between the $d_{B}$ in the case of $\mathrm{Al}_{2} \mathrm{O}_{3}$ (I) and (II) particles $100 \mathrm{~nm}$ or bigger and mode pore size. Consequently, it is thought that the arranged structures of primary particles of $12.2 \mathrm{~nm}$ and $108 \mathrm{~nm}$ are approximately the same under high pressure conditions of $1 \mathrm{GPa}$.

Also in the case of $\mathrm{MgO}$ (I), the pore diameters are roughly smaller than the primary particles' diameters and are of a dense structure in a relatively low pressure stage (Fig. 3). Although the powder is of a relatively large particle size of $200 \mathrm{~nm}$ compared with $\mathrm{Al}_{2} \mathrm{O}_{3}$ (I), the mode pore size is conspicuously reduced with an increase in pressure. Also with $\mathrm{MgO}$ (II) and (III), the pore diameters become smaller in proportion with an decrease in particle size but a tendency similar to that of 


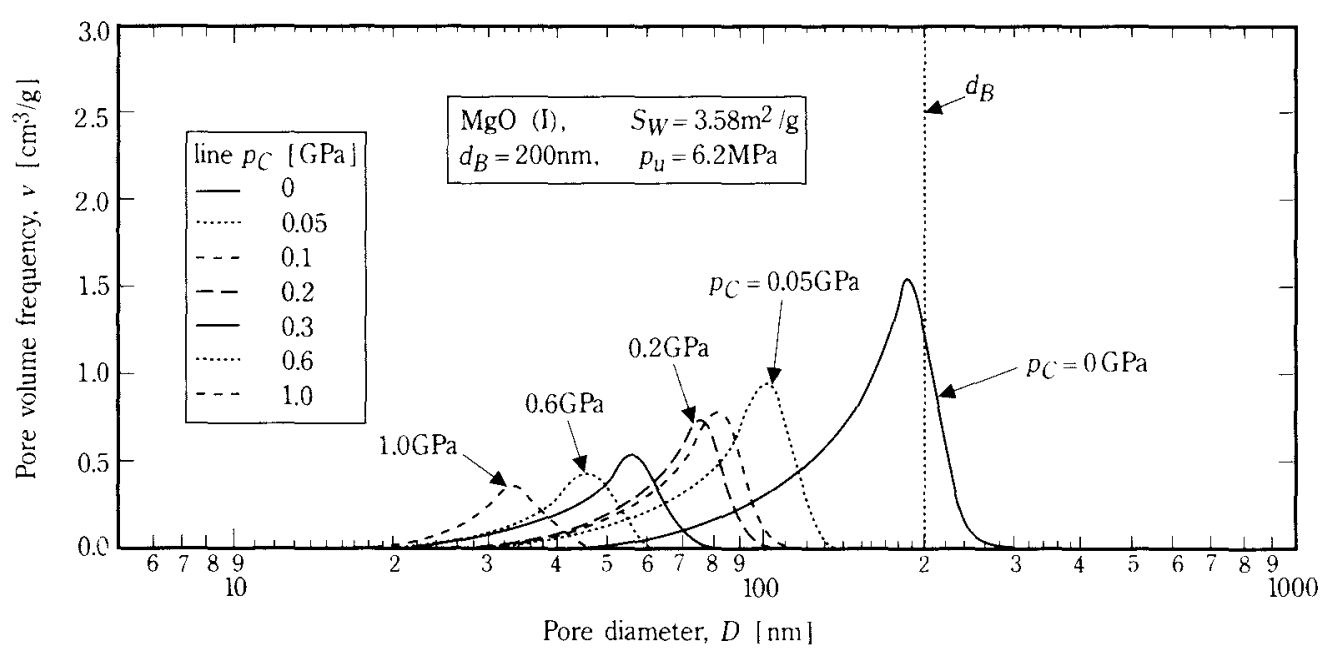

Fig. 3 Pore size distribution in compacts of MgO powders measured by mercury porosimetry. Estimated mean particle size was $200 \mathrm{~nm}$

$\mathrm{MgO}$ (I) was obtained. With $\mathrm{MgO}$ (IV), as with $\mathrm{Al}_{2} \mathrm{O}_{3}$ (III), pores with diameters several times larger than the primary particles' diameter are present under low pressure conditions but the pore diameters decrease with an increase in pressure and at $1 \mathrm{GPa}$, open pores larger than $6 \mathrm{~nm}$ are hardly observable.

In regard to powders on which experiments were made, the ratio between the mode pore size $\left(D_{m}\right)$ and the primary particle size $\left(d_{B}\right)$ under various pressure conditions was obtained and the relations with the compacting pressure are shown in Figs. 4(a) and (b). With $\mathrm{Al}_{2} \mathrm{O}_{3}$ (I) and (II) $\left(d_{B}=269,108 \mathrm{~nm}\right)$, in which the compact relative density does not change much with high pressure applications, a reduction down to around $D_{m} / d_{B}=0.6$ was seen under low pressure conditions of $0.05 \mathrm{GPa}$. However even by applying a higher pressure of $1 \mathrm{GPa}, D_{m} / d_{B}$ drops only to 0.4 , indicating that the packed structure of particles does not change much (Fig. 4 (a)). On the other hand, with $\mathrm{Al}_{2} \mathrm{O}_{3}$ (III) or $\mathrm{SiO}_{2}$ (I), (II) and $\mathrm{MgO}$ (IV), which consist of fine particles of $100 \mathrm{~nm}$ and less, $D_{m} / d_{B}>>1$ at a low pressure stage but from around $0.3 \mathrm{GPa}$, the mode pore size became smaller than the particle size and at $1 \mathrm{GPa}$, it reached the same level as that of $\mathrm{Al}_{2} \mathrm{O}_{3}$ (I) and (II) $\left(d_{B}=269\right.$, $108 \mathrm{~nm})$ of $D_{m} / d_{B}=0.4$. The relation between $D_{m} / d_{B}$ and the compacting pressure also was approximated by a nearly straight line on a logarithmic graph and compared with $\mathrm{Al}_{2} \mathrm{O}_{3}$ (I) and (II), the slope of fine particles of around $10 \mathrm{~nm}$ particle size was about 5 times steeper. Also in the relation between the compact density and pressure shown in Fig. 1, the slope differed by about 5 times, roughly coinciding with the above. In the case of $\mathrm{MgO}$ (I), (II) and (III), the

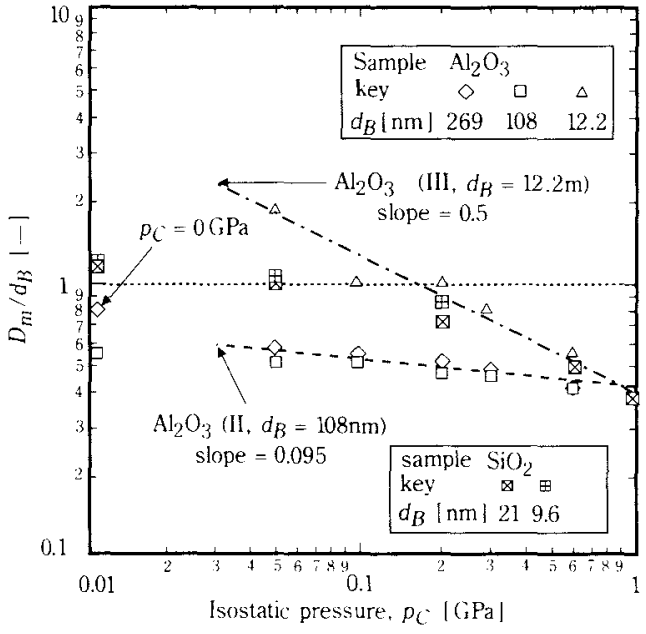

(a) $\mathrm{Al}_{2} \mathrm{O}_{3}$ and $\mathrm{SiO}_{2}$ powders

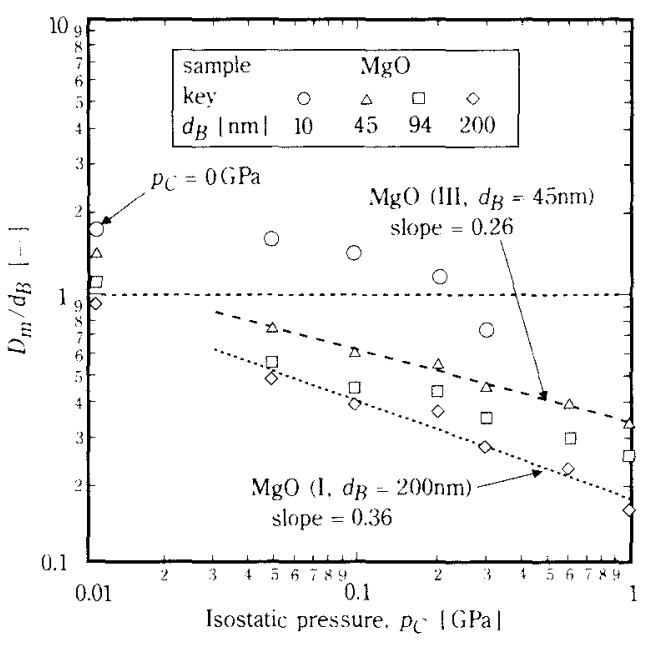

(b) $\mathrm{MgO}$ powders

Fig. 4 Ratio of mode pore size in powder compacts to mean particle diameter with cold isostatic pressure. 
mode pore size decreased with an increase in pressure and the slope indicated in the Figure by a straight line shows an intermediate value between that of $\mathrm{Al}_{2} \mathrm{O}_{3}$ (I), (II) and $\mathrm{Al}_{2} \mathrm{O}_{3}$ (III). As a result, $D_{m} / d_{B}$ at $1 \mathrm{GPa}$ decreased down to 0.2 or less.

Since a correlation is observed between the isostatic compacting pressure and the mode pore size as well as the compact density, the relation between the relative density $\left(p_{G} / p_{T}\right)$ and $D_{m} / d_{B}$ is shown in Fig. 5. Under low pressure conditions with a relative density not exceeding 0.3 , some dispersion of $D_{m} / d_{B}$ values may occur depending upon the particles but when high pressure is applied and the relative density becomes 0.5 or more, hardly any difference between particles is observed and the relation can be approximated by a straight line of slope -2 as shown in the Figure.

This result was compared with the packed structure of spherical mono-dispersed particles. It was assumed that the diameter of spheres which are in the air gap formed by the respective particles and which come into contact with each particle corresponds with the pore mode diameters. Table $\mathbf{2}$ summarizes the ratios $(D / d)$ between the particle diameters of each structure and the diameter of spheres which inscribe each particle as well as the relative densities. When the results in Table 2 overlapped with those of Fig. 5, the experiment values roughly coincided with the pore diameter/particle diameter ratio up to the packed model structure and the compact relative density. The slope gradient became approximately -2 and the spherical mono-dispersed particles $D / d$ coincided with the fine particles $D_{m} / d_{B}$ used in this study. The specific area converted particle size and mode pore sizes were both affected by the particle size distribution. However since both the converted particle size and the pore diameters were about the same, the effect due to the particle size distribution was offset and it was thought that they roughly coincided with the case of spherical mono-dispersed particles. Also in the case of $\mathrm{MgO}$ (I) where the relative density reached a maximum of $80 \%$, approximation was made by the straight line in the Figure. If it is to be assumed that densification progressed by mechanisms such as the deformation of primary particles, it can be presumed that the distribution

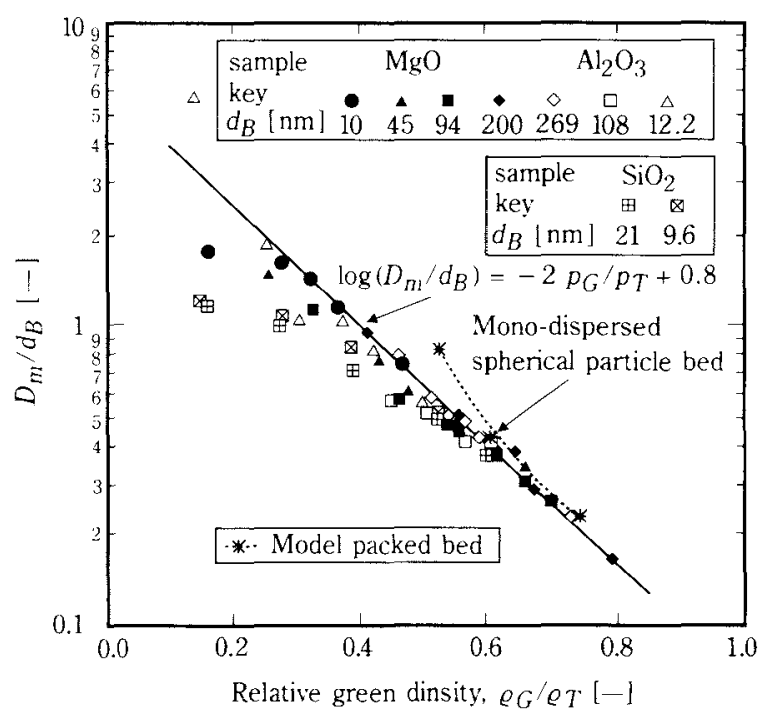

Fig. 5 Relations between ratio of mode pore size in powder compacts to mean particle diameter and relative density of powder compacts. Results of model packed bed using spherical and monosized particle were added

would divert from this straight linerelation. Therefore it is thought that densification progresses through a particle rearrangement mechanism.

The study on compact structure was organized by focusing on mode pore size and next, the mode pore size distribution was studied. As shown in the example given in Fig. 6, the pore size distribution can be approximated by Gauss distribution (Eq. 3) and not by the kind of particles or compacting conditions.

$$
v=k_{1} \exp \left\{\left(D-D_{m}\right)^{2} / k_{2}\right\}
$$

Here, $k_{1}$ is the pore volume frequency $(\nu)$ when the pore diameter $(D)$ is equivalent to Dm and corresponds to the height of the peak value of the pore diameter distribution while $k_{2}$ indicates the spread of distribution. To study the correlation between the respective parameters, the parameters were estimated from the pore diameter distribution of compacts obtained in this study and Fig. 7 shows the results of the relations between $k_{2}$ and the mode pore size $\left(D_{m}\right)$. The relation between the two is roughly a proportional relation and can be approximated by the straight line $\left(k_{2}=0.2 D_{m}\right)$ in the Figure. Especially in the case of $\mathrm{MgO}$, a good straight line relation exists and with changes in pore size distribution form

Table 2 Ratio of pore channel diameter to particle size and relative density of model packed beds for monosized spherical particles

\begin{tabular}{cccc} 
Packing structure & Simple cubic & Body-centered cubic & Hexagonal close packing \\
\hline Relative density & 0.524 & 0.605 & 0.741 \\
$D / d$ & 0.732 & 0.414 & 0.225
\end{tabular}




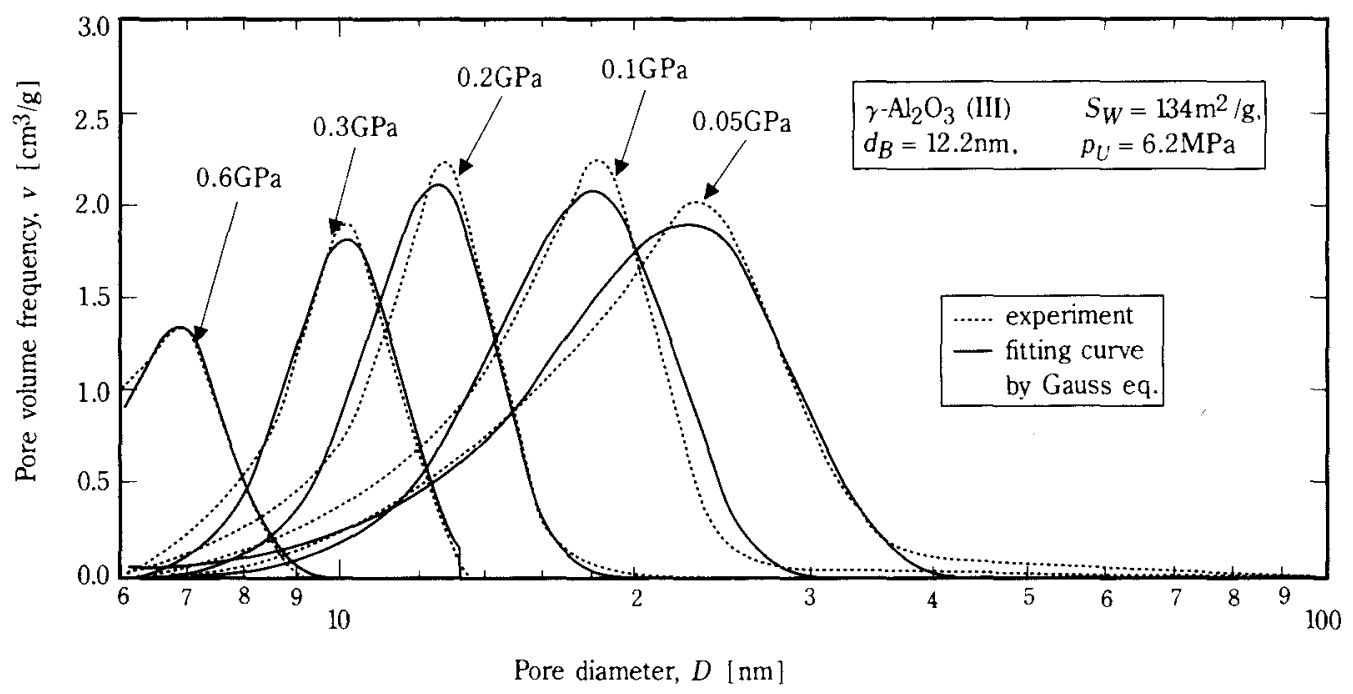

Fig. 6 Examples of curve fitting results for pore size distribution in compacts by Gauss distribution function (Eq. 2)

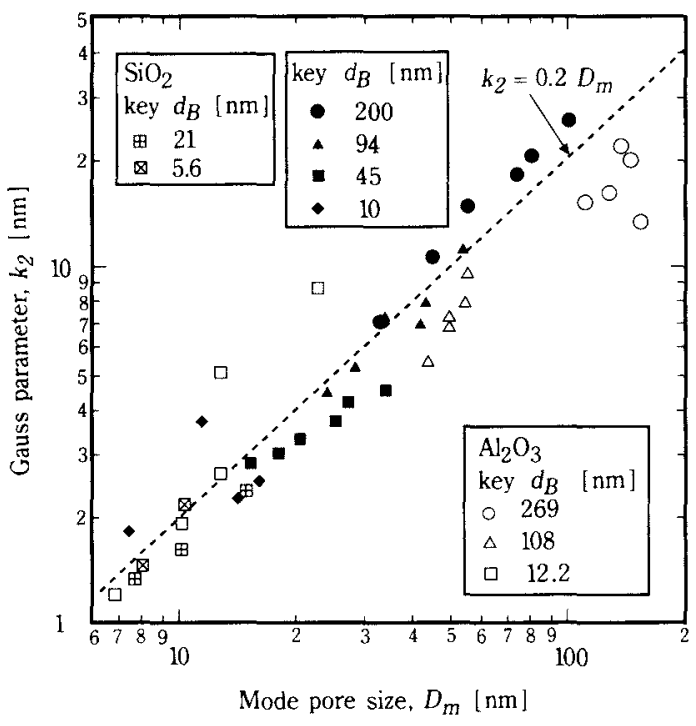

Fig. 7 Relations between parameter $k_{2}$ Eq. (2) and mode pore size in compacts

during the process of compacting with a slight pressure increase, only the mode pore size decreases, resulting in densification.

On the other hand, with $\mathrm{Al}_{2} \mathrm{O}_{3}$, the mode pore size $\left(D_{m}\right)$ and $k_{2}$ are not necessarily proportional and as shown in Fig. 8, with $\mathrm{Al}_{2} \mathrm{O}_{3}$ (III) which consists of ultra-ine particles, $k_{2} / D_{m}$ decreased with the application of compacting pressure and the distribution form changed. Also with $\mathrm{Al}_{2} \mathrm{O}_{3}$ (IV), the pore sizes reached $6 \mathrm{~nm}$ or less with a pressure of $0.2 \mathrm{GPa}$ or higher and although this is not shown in Figs. 7 and $\mathbf{8}$, a change in pore size distribution form was conspicuous. It is believed that with ultra-fine particles of $\mathrm{Al}_{2} \mathrm{O}_{3}$, the aggregate structure remaining from the low pressure stage gradually collapses

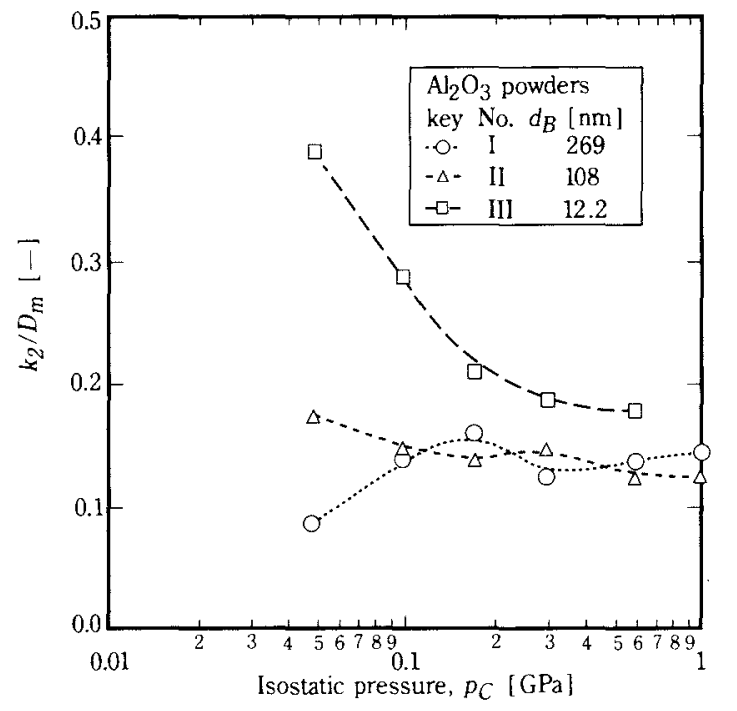

Fig. 8 Change in the ratio of parameter $k_{2}$ in Eq. (2) to mode pore size in $\mathrm{Al}_{2} \mathrm{O}_{3}$ powder compacts with increase of cold isostatic pressure

during the pressurizing process and therefore changes in the pore size distribution form could be seen.

\section{Discussion}

In regard to the densification mechanism produced by isostatic high pressure compacting of ultra-fine particle packed beds, the rearrangement of particles following the collapse of the aggregate structure or elastic deformation at the particle contact point and collapse of the particles themselves can be considered. From the results shown in Fig. 5, it can be presumed that the rearrangement of particles is dominant in the densification mechanism but by computing the compression stress at the particles' contact point 
as wein as the tensile stress inside the particles during the pressure application process and by comparing the hardness of the particles with the collapsing strength, a quantitative study on the possibility of particle deformation and collapse was made. When isostatic stress $\left(p_{C}\right)$ is applied on particle compacts, the force $(P)$ generated at the particles' contact point may be obtained using the following equation if the packed bed is a uniform and isotropic random bed ${ }^{12,16)}$.

$P=p_{C} d_{B}^{2} \mathcal{E} /(1-\mathcal{E})$

Where, $\mathcal{E}$ is the air gap ratio of the compact and from Fig. 1, the compact density is proportional to the logarithm of the isotropic stress $\left(p_{C}\right)$; therefore $\left(\varrho_{G} / \varrho_{T}=1-\mathcal{E}=a \log P_{c}+b\right)$. Equation (4) can be rewritten as Equation (5) using constants a and $b$.

$$
P=p_{C} d_{B}^{2}\left\{1-\left(a \log p_{C}+b\right)\right\} /\left(a \log p_{C}+b\right)
$$

In the case of ultra-fine particles, aggregate bodies may be present and the assumption of a uniform isotropic random structure may not be satisfied. However, from the measurement results of pore size distribution in Fig. 3, it can be seen that aggregate structures are nearly collapsed under high pressure conditions of $0.2 \mathrm{GPa}$ and above, and there is a difference in force between the inside and the surface of the aggregate structure even in the low pressure stage but by assuming that $P$ of Equations (4) and (5) is an average value, it is believed that such assumption is justified. Fig. 9 shows the results obtained by deriving the constants $a$ and $b$ for each powder of Fig. 1 and converting the force which acts on the contact points. As the particles become larger, the contact points in the compacts become fewer and therefore the force that acts on the contact points becomes greater. Also, the slopes in the Figure have all a gradient smaller than 1 and the forces applied as compacting pressure and at contact points are not proportional. Also with $\mathrm{Al}_{2} \mathrm{O}_{3}$ (III) and (IV) and $\mathrm{MgO}$ (IV) in which the primary particle sizes are not larger than $15 \mathrm{~nm}$, the force acting on the contact points hardly changes at pressures of $0.03 \mathrm{GPa}$ or less and it can be seen that the force which was applied by rearrangement of particles is dispersed.

Next, the average stress generated at the particle contact point by force $(P)$ was estimated ${ }^{9,14)}$. Assuming a spherical particle, the particle contact point is subject to an elastic deformation due to force $(P)$ as

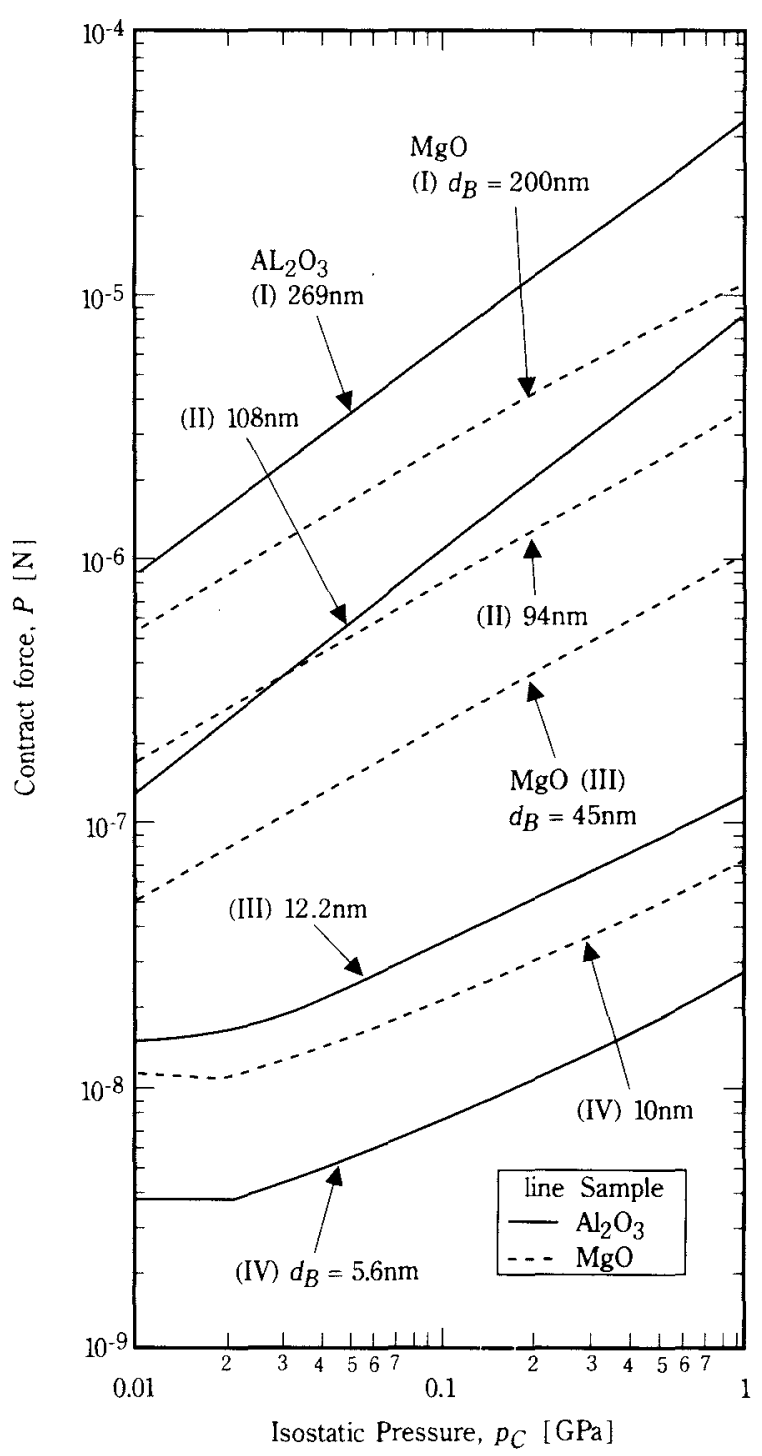

Fig. 9 Estimated mean force at contact point between particles in compacts according to Rumpf's equation (Eq. 3)

shown in Fig. 10(a) and the elastic displacement ( $\Delta$ ) is expressed by the following equation using Hertz formula.

$$
\Delta=\left\{9 P^{2}\left(1-\nu^{2}\right)^{2} /\left(2 d_{B} Y^{2}\right)\right\}^{1 / 3}
$$

Where, $\nu$ is Poisson's ratio and $Y$ is Young's modulus. To evaluate the elastic deformation characteristics of the particle from its hardness, the area $(A)$ of the osculating circle following elastic deformation is obtained geometrically using the following equation.

$$
A=\pi r^{2}=\pi\left(\Delta d_{B} / 2-\Delta^{2} / 4\right)
$$

The displacement amount at the contact point is calculated using Equation (6) and the results of the calculation of $P / A$ as the simplified mean stress at the contact point by applying Equations (5) and (7) of $P / A$ is given in Fig. 10 (b). For Poisson's ratio and 


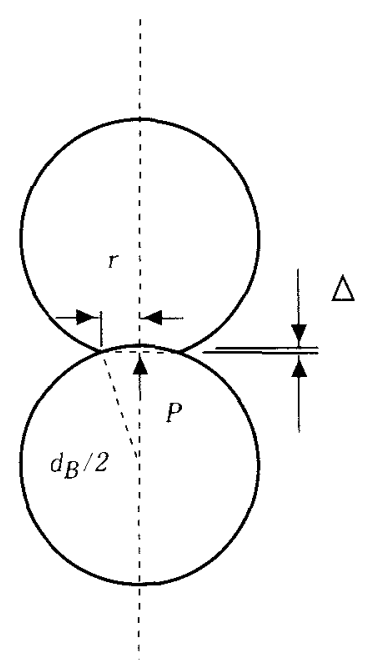

(a) Scheme of contact point between particles.

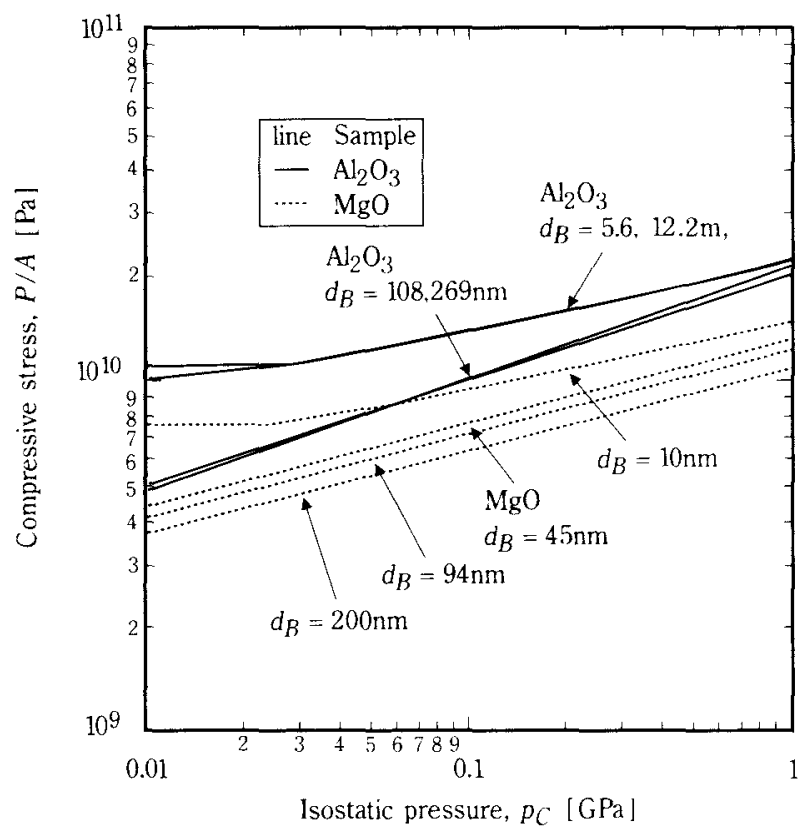

(b) Estimated mean compressive stress at contact point by Equation (5) and (7).

Fig. 10 Estimation of elastic deformation and mean compressive stress at contact point between particles.

Young's modulus, $\nu=0.25, Y=420 \mathrm{MPa}$ for $\mathrm{Al}_{2} \mathrm{O}_{3}$, and $\nu=0.25, Y=248 \mathrm{MPa}$ for $\mathrm{MgO}$ were used ${ }^{3}$. The mean stress at the particle contact point differed somewhat depending on the type and size of particles, but it remained within the range of $4 \mathrm{GPa}$ to 20 $\mathrm{GPa}$. Since the hardness of particles is around 25 $\mathrm{GPa}$ for $\mathrm{Al}_{2} \mathrm{O}_{3}$ and $15 \mathrm{GPa}$ for $\mathrm{MgO}^{3)}, \mathrm{P} / \mathrm{A}$ had about the same value as the hardness value or was slightly lower. Although the contact points may be plastically broken down locally, the stresses at the contact surfaces were nearly the same as the hardness and an occurrence of a plastic deformation larger than the value of $\Delta$ obtained from the elastic displacement is inconceivable. Table 3 shows the ratio between the displacement amount $\Delta$ at $1 \mathrm{GPa}$ for each powder obtained from Equation (6) and the particle size. The deformation amount at a contact point was estimated to be about $3 \%$ of the particle size at the most. With a plastic deformation of this magnitude, it is thought that the effect of the deformation of a particle contact point on the pore size between particles, on the increase in compact density, or on making the pore size finer is slight.

Finally, the effect due to fracture of particles was studied. By applying a compression force $(P)$ to the particle contact points, the tensile stress $\left(\sigma_{T}\right)$ generated near the particle contact point was obtained using the following equation ${ }^{14)}$.

$$
\begin{aligned}
\sigma_{T} & =\{(1-2 \nu) / 3\}\left\{3 P /\left(\pi \mathrm{r}^{2}\right)\right\} \\
& =\{(1-2 \nu) / 2\}(P / A)
\end{aligned}
$$

The tensile stress generated near the particle contact point obtained using this equation was $(1-2 \nu) / 2$ times the mean compression stress and when $\nu=$ 0.25 was used, it became $1 / 4$ times. In Table 3 , the tensile stresses of the corresponding powders at 1 $\mathrm{GPa}$, obtained using Equation (8), are shown but they are within a range of $2.5-5 \mathrm{GPa}$. This value, compared with the theoretical strength of alumina monocrystals, $\left(\sigma_{\text {th }}-\mathrm{E} / 10=42 \mathrm{GPa}\right)^{17}$ or with the actual measured value $\left.(15 \mathrm{GPa})^{17}\right)$ of the tensile strength of alumina monocrystal whiskers, is sufficiently small. The tensile stress obtained using Equation (8) is generated within a depth range of about twice the contact radius $r$ of the particles from the particle contact surface and rapidly decreases inside the particle ${ }^{14)}$. The contact radius $r$ at a compact pressure of $1 \mathrm{GPa}$ was obtained geometrically using the following Equation and the calculated results are shown in Table 3.

$r=\left(\Delta d_{B} / 2-\Delta^{2} / 4\right)^{1 / 2}$

In either case, the contact radius $r$ is about $10 \%$ of the particle diameter and even with $\mathrm{Al}_{2} \mathrm{O}_{3}$ which has the largest particle size, it is $28 \mathrm{~mm}$. From the Weibull theory ${ }^{17)}$ in which the material strength is dominated by the maximum defect in the material, the maximum defect length $c$ which is concerned with fractures near the particle contact point due to the generated tensile stress $\sigma_{T}$ is assumed to be equivalent to a range of about $2 \mathrm{r}$ within which the maximum tensile 
Table 3 Estimated deformation of particle, tensile stress and tensile strength at contact point. Isostatic pressure was equal to $1 \mathrm{GPa}$.

\begin{tabular}{|c|c|c|c|c|c|c|c|c|}
\hline \multirow{2}{*}{$\begin{array}{c}\text { Samples } \\
\ldots \ldots \ldots \ldots \ldots . . . \\
d_{B}[\mathrm{~nm}]\end{array}$} & \multicolumn{4}{|c|}{$\mathrm{Al}_{2} \mathrm{O}_{3}$} & \multicolumn{4}{|c|}{$\mathrm{MgO}$} \\
\hline & 269 & 108 & 12.2 & 5.6 & 200 & 94 & 45 & 10 \\
\hline$\Delta / d_{B}[\%]$ & 2.2 & 2.4 & 2.6 & 2.6 & 1.8 & 2.3 & 2.7 & 3.3 \\
\hline$\sigma_{T}[\mathrm{GPa}]$ & 4.9 & 5.0 & 5.3 & 5.3 & 2.6 & 2.9 & 3.2 & 3.5 \\
\hline$r[\mathrm{~nm}]$ & 28 & 12 & 1.4 & 0.63 & 19 & 10 & 5.2 & 2.7 \\
\hline$\sigma_{e}[\mathrm{GPa}]$ & 10 & 15 & 42 & 42 & 12 & 17 & 23 & 32 \\
\hline
\end{tabular}

strength is generated. From this assumption, the fracture strength $\sigma_{e}$ near the contact point was estimated from the following equation.

$\sigma_{e}=K_{I C} c^{1 / 2 / 1.26}$

Where, $K_{I C}$ is the critical stress intensity factor for brittle materials and the value differs depending on the literature and measuring method but since a value of around $2 \sim 4 \mathrm{MNm}^{3 / 2}$ for $\mathrm{Al}_{2} \mathrm{O}_{3}$, and $3 \mathrm{MNm}^{3 / 2}$ for $\mathrm{MgO}$ was obtained, $3 \mathrm{MNm}^{3 / 2}$ was used. Table 3 shows the results of the calculation of the fracture strength near the contact point $\sigma_{e}$ with $c=2 \mathrm{r}$. For $\mathrm{Al}_{2} \mathrm{O}_{3}$ (III) and (IV), since $\sigma_{e}>\sigma_{\text {th }}$ was obtained, $\sigma_{e}=\sigma_{t h}$ was used. From this result, it can be estimated that the strength near the fine particle contact point of $1 \mu \mathrm{m}$ and less used in this report was not lower than $10 \mathrm{GPa}$ which is close to the theoretical strength. Consequently, it can be considered that with a generated stress of several GPa, fracture of particles hardly occurs.

Observations of compacts using an electron microscope were made on compacts of $\mathrm{Al}_{2} \mathrm{O}_{3}$ (II) and $\mathrm{MgO}$ (I) which are of relatively large particle size. Their particle shapes were maintained even under isostatic high pressure compacting conditions of $1 \mathrm{GPa}$ and no notable particle fracture or deformation was observed. The relation between the relative density shown in Fig. 5 and the mode pore size/particle size coincided with the model packed structure of spherical mono-dispersed particles and in consideration of this, there was little possibility of substantial plastic deformation or particle fracture occurring at contact points even under high pressure conditions. It is thought that densification occurred by rearrangement of primary particles following the collapse of aggregate structures.

\section{Conclusion}

Using ultra-fine particles of $\mathrm{Al}_{2} \mathrm{O}_{3}, \mathrm{MgO}$, and $\mathrm{SiO}_{2}$ of various particle sizes, isostatic high pressure compacting under pressures of up to $1 \mathrm{GPa}$ was conducted and from the results obtained through evaluation and analysis of the compacting characteristics and compact structures, the following conclusions were reached.

1) Isostatic high pressure of $1 \mathrm{GPa}$ is extremely effective for the densification of ultra-fine particle compacts with particle sizes of $15 \mathrm{~nm}$ and less, irrespective of the type of powder. Strong and coarse aggregate structures completely collapse under high pressure, and the relative density increased up to a maximum of $60 \%$. It was also possible to make the pore size inside the compact smaller than the primary particle size.

2) With $\mathrm{Al}_{2} \mathrm{O}_{3}$ powders of $100 \mathrm{~nm}$ and a larger particle size, the density and pore size did not change appreciably with an increase in pressure. High pressures of $0.6 \mathrm{GPa}$ or above were not very effective for the densification or for making air gaps in compacts smaller. On the other hand, with $\mathrm{MgO}$ powders, even for particle sizes of 100 $\mathrm{nm}$ and above, increased densification and reduction in pore size were seen with an increase in pressure and a maximum relative density of $80 \%$ and a reduction to $20 \%$ or less of the mode pore size with respect to the specific surface converted diameter were achieved.

3) The relation between the mode pore size/primary particle size ratio and the compact relative density was roughly approximated by a single straight line on a semi-logarithm graph. Also, by estimating the force applied at the particle contact points, the generated stress, and the maximum tensile stress generated inside the particles, and by making comparisons with the particle strength and the particle fracture yield value, it was confirmed that no notable plastic deformation or particle fracture phenomena at the contact points had occurred. Consequently, within the experiment scope of this study, densification was enhanced by the primary particle rearrangement mechanism following the collapse of aggregate structures. 


\section{[Acknowledgements]}

Gratitude is expressed for the support provided for this study by "the Toden Memorial Scientific Technology Research Center Foundation research assistance", and "the Ministry of Education Scientific Research subsidy (General Research A)".

\section{Nomenclature}

$A=$ area of contact circle between particle $\left[\mathrm{nm}^{2}\right]$

a $=$ parameter in Eq. (3) [-]

$b \quad=$ parameter in Eq. (3) [-]

$c=$ maximum flow length in contact area of particle

$D=$ pore diameter in compacts

[nm]

$d \quad=$ particle diameter

$d_{B}=$ mean particle diameter estimated from specific surface area by BET method [nm]

$D_{m}=$ mode pore diameter in compacts

$k_{1} \quad=$ parameter in Gauss equation

$k_{2} \quad=$ parameter in Gauss equation

[nm]

$[\mathrm{nm}]$

$K_{I C}=$ critical stress intensity factor for brittle material

$P \quad=$ force at contact point between particles in compacts

$p_{C}=$ cold isostatic pressure

[GPa]

$p_{U}=$ pressure of uni-axial pre-pressing

[GPa]

$r=$ radius of contact circle between particles [nm]

$S_{W}=$ specific surface area by BET method $\left[\mathrm{m}^{2} / \mathrm{g}\right]$

$v=$ pore volume frequency $\quad\left[\mathrm{cm}^{3} / \mathrm{g}\right]$

$Y=$ Young's modulus $\quad[\mathrm{MPa}]$

$\Delta=$ deformation at contact point between particles

[nm]

$\mathcal{E} \quad=$ porosity in powder compacts $\quad[-]$

$\nu=$ Poisson's ratio [-]

$\sigma_{e} \quad=$ estimated tensile strength of contact area of particle

$[\mathrm{Pa}]$

$\sigma_{T} \quad=$ tensile stress in particle

$[\mathrm{Pa}]$

$\sigma_{\text {th }}=$ theoretical tensile strength of materials $[\mathrm{Pa}]$

$\varrho_{G}=$ density of powder compacts $\quad\left[\mathrm{kg} / \mathrm{m}^{3}\right]$

$\varrho_{T}=$ powder true density $\quad\left[\mathrm{kg} / \mathrm{m}^{3}\right]$

\section{Literature cited}

1) Abe, O., S. Kanzaki and H. Tabata: J. Ceram. Soc. Jpn., 97, 32-37 (1989)

2) Abe, O., S. Aoki, S. Kanzaki and H. Tabata: ibid., 97, 432-38 (1989)

3) "Fine Ceramics Jiten", (1987), Gihoudou Shuppan, Japan

4) Horvath, J., R. Birringer and H. Gleiter: Solid State Communication, 65, 319-22 (1987)

5) Kamiya, H., H. Suzuki, T. Ichikawa and G. Jimbo: Ceramic Eng. and Sci. Proc., 13 (7-8), 563-70 (1992)

6) Kamiya, H., H. Suzuki, D. Kato and G. Jimbo: J. Am. Ceram. Soc., 76(1), (1993) in press

7) Kumagai, M. and G.L. Messing: ibid., 68, 500-05 (1985)

8) Karch, J., R. Birringer and H. Gleiter: Nature, 330, 556-58 (1987)

9) Mindlin, R.D. and N.Y. New York: J. Applied Mechanics, 259-65 (1949)

10) Nishida, A., A. Ueki and H. Masuda: J. Mat. Sci. Jpn., 36, 1157-61 (1987)

11) Reed, J.S.: "Introduction to the Principles of Ceramics Processing", p.339, John Wiley and Sons, New York (1982)

12) Rumpf, H.: Chem. Ing. Tech., 42, 538-40 (1970)

13) Sacks, M.D. and T.Y. Tseng: J. Am. Ceram. Soc., 67 (8), 526-32 (1984)

14) Timoshenko, S.P., and J.N. Goodier: "Theory of Elasticity, Third Edition", pp.409, McGraw Hill (1970)

15) Tseng. T.Y. and M.D. Sacks: J. Am. Ceram. Soc., 71, 841-44 (1988)

16) Tsubaki, J. and G. Jimbo: Powder Technology, 37, 219-27 (1984)

17) Yokobori, T.: "Zairyou Kyodogaku", p.9, Iwanami Zensyo, (1974)

18) Kirchener, H.P.: Eng. Fract. Mec., 10, 283-88 (1978) 